своих возможностей , используют интеллектуальные ресурсы, незамедлительно

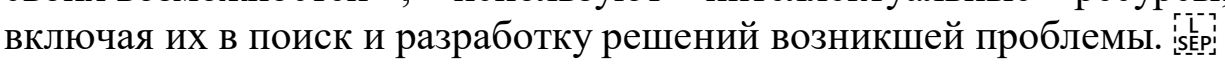

$$
* * *
$$

1. Знаков В.В. Психология понимания мира человека. М.: Изд-во «Институт Психологии РАН», 2016.

2. Кашапов А.С. Социально-психологическая адаптированность студентов: проблемы и решения: монография. Ярославль, ИПК «Индиго», 2015.

3. Леонтьев Д.А. К психологии поступка // Экзистенциальная традиция: философия, психология, психотерапия. Ростов н/Д., 2006. Вып. 2. С. 153-158.

4. Сергиенко Е.А., Лебедева Е.И., Прусакова О.А. Модель психического в онтогенезе человека. М.: Изд-во «Институт Психологии РАН», 2009.

5. Сергиенко Е.А., Виленская Г.А., Ковалева Ю.В. Контроль поведения как субъектная регуляция. М.: Изд-во «Институт Психологии РАН». 2010.

\title{
Цзоу Лихуэй \\ Исследование развития способности к культурной эмпатии при аудиовизуальном обучении русскому языку в университете
}

Хэйлунцзянский государственный технологический институт (КНР, Цзиси)

doi 10.18411/spc-12-01-2018-06

idsp 000001:spc-12-01-2018-06

\section{Аннотация}

Язык и культура тесно связаны. Обучение русскому языку - это изучение языка, что также неотделимо от изучения культуры. Культурная эмпатия является ключом к тому, чтобы сделать русский язык действительно эффективным, а также важной гарантией эффективного межкультурного общения. Развитие культурной эмпатии также является проблемой, о которой в последние годы обращают внимание преподаватели университетов России. Эта статья начинается с теории культурного сочувствия в межкультурной коммуникации и исследует, как развивать культурную эмпатиюу студентов в университете в русском аудиовизуальном обучении, понимая реальную ситуацию сочувственных способностей студентов.

\section{Abstract}

Language and culture are closely related. The teaching of Russian is the study of the language, which is also inseparable from the study of culture. Cultural empathy is the key to making the Russian language really effective, and also an important guarantee of effective intercultural communication. The development of cultural empathy is also a problem, which teachers of Russian universities have been paying attention to in recent years. This article starts with the theory of cultural sympathy in intercultural communication and explores how to develop cultural empathy among students at the university in Russian audiovisual learning, understanding the real situation of students' sympathetic abilities.

В университетах Китая, русское аудиовизуальное обучение, является профессиональным и обязательным. Основная практика методов обучения сочетается с преподаванием других курсов для достижения цели обучения, повышения уровня слуха,восприятия и речи. Слушание и разговорная подготовка занимают важное место в изучении русского языка. Независимо от точки зрения преподавания или языкового инструментализма или развивающейся тенденции преподавания иностранных языков, обучение «прослушиванию» и «разговором» является основными задачами преподавания иностранных языков. Слушание часто играет фундаментальную и решающую роль в умении говорить, например, слушать, говорить, читать, писать и 
переводить. Это также незаменимый способ словесного общения. Курс учит не только изменять традиционный режим обучения, но и изменять традиционный учебный контент, особенно для студентов, способных развивать контент. Культура способности к эмпатии заключается в том, чтобы позволить учащимся одновременно изучать язык, понимать культуру, достигать цели практической компетентности студентов и культурных достижений для улучшения способности учащихся к межкультурной коммуникации. Поэтому нельзя игнорировать университетское аудиовизуальное обучение, развивающее культурнуюэмпатию.

1. Эмпатия и культурная эмпатия.

Термин «эмпатия» был впервые сформулирован как эстетически приятная концепция Роберта Виссера, немецкого эстетиста, в его статье «Ощущение визуальной образованности», написанной в 1873 году. В своей книге «История западной эстетики» китайский ученный ЧжуГуанцян сказал: «Какова роль эмпатии? Проще говоря, это означает, что, глядя на что-то снаружи, в жизни есть что-то, как будто у него также есть чувства, мысли, эмоции, желания и действия».

Знаменитый немецкий ученыйв области психологииТеодор Липпс в своей статье «Эмпатия, внутреннее мимесис и чувство удовлетворения» сказал: «Эмпатия - это тот факт, что здесь определяет самобъект».

Впервые в 1990-х годах профессор ХэЦзижань выдвинул концепцию «эмпатии» во внутреннем английском академическом сообществе. Он считал, что «изучающие язык студенты должны понимать и ощущать культуру страны, язык которой ониизучают, и уметь ставить себя в культурном контексте друг друга при изучении и использовании языка».

Арнольд в книге «Влияние языкового обучения» утверждает, что «эмпатия - это сознательное или поведенческое представление о собственной точке зрения».

Разные ученые дают свое собственное определение культурной эмпатии. Например, Самовар и Портер (2001)считают, что культурнаяэмпатия включает в себя два уровня: первый - это эмоциональный уровень, онначинается с подтверждения собственных положительных эмоций и способности управлять своими эмоциями в позитивном ключе, чтобы не было предубеждения и стереотипизации действий. Вовторых, когнитивное измерение, которое включает в себя возможность интерпретировать и различать мышление и мысли других людей, критическое мышление, логику, намерение и риторику.

Китайский ученый - ГаоЮнчен (2005) рассматривает культурную эмпатию, как своего рода психологический опыт, эмоциональное перемещение и когнитивное обращение в процессе межкультурной коммуникации, для обеспечения плавного общения между разными культурами, то есть сознательно превосходить национальность языка и культуру устанавливать психологическую сдержанность, стоящую в другой культурной модели психологического мышления этой тенденции.

Юань Чжимин (YuanZhiming, 2008) и другие считают, что культурнаяэмпатия относится к коммуникативному субъекту, сознательно преобразующему культурное положение, сознательно превосходящему клише и структуру рамок родной культуры в общении, избавляясь от ограничения собственной культуры, ставя себя в другой культурный режим. Реалистично чувствовать, понимать и принимать другую культуру. Это не только мост и связь между языком, культурой и эмоциями, которые соединяют предметы и объекты в межкультурной коммуникации, а также эффективные навыки общения, искусства и способности. 
Согласно определениям, которые сделаны вышеупомянутыми учеными, автор считает, что культурная эмпатия заключается в том, что коммуникативный субъект сознательно избавляется от первоначальной тенденции мышления и погружается в режим целевой языковой культуры. Он думает с культурной точки зрения и осознает эмоциональные изменения других, для достижения понимания и принятия намерений других людей, ценностей, образа мышления, эмоционального отношения,обычаев, и других культурных факторов.

2. Российский статус сочувствия к профессиональной эмпатии со звуком

Для обучения русскому языку при помощи«аудиовизуально-говорящего обучения» требуется определенное знание русской культуры, которое уже давно преподается подавляющим большинством китайских педагогов, но в то же время, обучение русскому языку и культуре в Китае не является идеальным.

Чтобы лучше понять текущую ситуацию развития культурной эмпатии у студентов, изучающих русский язык, мной проведено анкетирование китайских студентов 16-го уровня изучения русского языка в количестве 50 человек.

Результаты исследования показали, что ни один из опрошенных студентов не принадлежит к очень сильному диапазону эмпатии. 4 (8\%) человека относятся к диапазону сильной эмпатии. 14 (28 \%) человек относятся к диапазону средней силы эмпатии. 30 (60\%) человек принадлежат к слабому диапазону эмпатии. 2 (4\%) относятся к очень слабому уровню эмпатии. Это показывает, что уровень эмпатии большинства студентов умеренно слабый.

Согласно результатам данного опроса, я намерена изучить, как преподаватели университета могут развивать культурную эмпатию у студентов при помощи русского «аудиовизуально-говорящего обучения», для обеспечения большей помощи их обучению в России.

3. Предложения по обучению студентов эмпатии при помощи российского аудиовизуального обучения.

Культурная эмпатия является предпосылкой культурного общения. Коммуникационная деятельность, умеренная культурная эмпатия для лучшего общения, для достижения эффективности коммуникации, межкультурного общения для достижения успеха. Поэтому в университетском российском аудиовизуальном обучении преподаватели должны не только передавать знания русского языка, но также должны уделять внимание обучению знаниям русской культуре, использовать различные способы для повышения осведомленности студентов о межкультурном общении, направлять студентов к культурному сопереживанию, достигать цели межкультурной коммуникации.

Во-первых, классное русское аудиовизуальное обучение совместно с преподаванием русской культуры.

Язык и культура неразрывно связаны. Только понимая и овладевая культурой, воплощенной в языке, мы действительно можем понять язык. В соответствии с требованиями обучения преподаватели могут внедрять российские культурные знания, преподавая русский аудиовизуальный и разговорный язык, и объяснять повседневную жизнь, способы мышления, обычаи, религию и другие аспекты людей в России. Они должны планировать систематически укреплять российскую культуру Обучение для того, чтобы студенты в процессе обучения продолжали углублять, укреплять и совершенствовать понимание многокультурных знаний, тем самым способствовать культивированию культурной эмпатии. Кроме того, преподаватели должны хорошо 
использовать мультимедийные методы обучения, чтобы студенты могли более глубоко понимать российскую культуру через музыку, фотографию, новости и видеоматериалы.

Во-вторых, необходимо смотреть русское оригинальное кино.

В русском аудиовизуальном обучении преподаватели могут демонстрировать отличное русское оригинальное кино, связанное с учебным контентом, для того, чтобы студенты погрузились в русский язык, мышление, обычаи, культуру и жизнь русского народа. Это улучшит восприятие российской культуры. Затем преподаватели могут использовать панельные дискуссии или руководить студентами, чтобы воссоздать культурную сцену в фильме через ролевую игру, вызвав любопытство и привлекая студентов к русской культуре. Наконец, вдохновляя учеников, преподаватели могут заставить обучающихся задуматься о различиях между родной культурой и русской культурой.

В-третьих, для осуществления различных внеучебных мероприятий.

Культивирование культурной эмпатии студентов не должно ограничиваться только аудиторией. Вне университета одинаково справедливы российские аудиовизуальные классы, организующие студентов для проведения разнообразных внеучебных мероприятий по местным культурам и российским культурным различиям. Такие, как проведение конкурсов русской речи, русского пения, чтение русских стихов, конкурс российских эссе, проведение российского радио, театрализованное представление о России и другие мероприятия в средствах массовой информации, семинары на русском языке и организация мероприятий на русском языке. Осуществляя разнообразные внеклассные мероприятия, мы можем объединить многокультурные знания студентов в атмосфере культурных знаний, еще больше укрепить понимание студентами русской культуры и достичь цели эффективного повышения культурного сочувствия студентов.

В-четвертых, организовать поездку студентов в Россию для российской культурной практики.

Поездка в Россию для проведения культурной практики имеет решающее значение, тур и учебная практика тесно интегрированы и обучают студентов проявлять инициативу, чтобы заниматься культурными исследованиями, сознательно осуществлять культурную эмпатию. Китайские студенты, которые много лет изучают русский язык, глубоко погружаются в культурную среду России, посетив страну в своей «языковой практике», активно контактируют с обычаями и привычками в еде и т. д. Они начинают тонко ощущать языковой образ мышления в межкультурной коммуникации. Различия, сравнивая сходства и различия между культурами Китая и России, изучают и понимают прикладную среду на разных языках. Например, в 2017 году Хэйлунцзянский государственный технологический институт, г.Цзиси направил в общей сложности 26 человек для участия в обучении в российских университетах, a также в ознакомительных целях. Проект способствовал повышению способности китайских студентов к русскому языку, расширил их горизонты восприятия русского языка и обогатил знаниями о России.

Таким образом, культурная эмпатия - важная часть российской коммуникативной компетентности. Культурная эмпатия является незаменимым звеном и важным элементом в преподавании русского языка при помощи «аудиовизуальноговорящего обучения» в университете. На фоне нового этапа университетской реформы преподавания русского языка при помощи «аудиовизуально-говорящего обучения»преподаватели не только должны изменить традиционные методы и формы обучения, но и культивировать способность к культурной эмпатииу студентов под 
руководством правильной теории обучения культурной эмпатии, что позволит улучшить способность студентов к межкультурному общению, заставить их действительно учиться использовать русский язык.

Работа выполнена по главному научному проекту провинции Хэйлунцзяна № WY 2017097-С «Исследование культуры эмпатии в области межкультурной коммуникации студентов специильности русского языка».

\section{$* * *$}

1. ЧжуГуанцян.История западной эстетики. Пекин: Издательский дом народной литературы.2002.С. 589-590.朱光潜。西方美学史。人民文学出版社。2002年。第589-590页。

2. Цзян Конгян Избранные произведения западной эстетики 19-ого века (немецкий том), Издательство Фуданского университета, 1990. 606 c. 蒋孔阳。《十九世纪西方美学名著选》(德国卷) 。复旦大学出版社。1990 年。第 606 页

3. ХэЦзыжань.Прагматическаяэмпатия в речевом сообщении.Обучение иностранным языкам и

$$
\text { Август }
$$

1991

года.

C.

14.何自然。言语交际中的语用移情。外语教学与研究。1991年8月。第11-14页。

4. Arnold.Affect in Language Learning.Cambridge:Cambridge University Press.2000。

5. Samovar L.A.\& Porter R.E.Communication between Cultures(4th edition) .Cambridge:Wadsworth Publishing Company.2001.

6. ГаоЮнчен. Ценность и культивирование культурной эмпатии в межкультурной коммуникации [J]. Обучение языкам и иностранным языкам, 2005. (12).С 17 19.). 高永晨。跨文化交际中文化移情能力的价值与培养。外语与外语教学。2005。(12)第17-19页。

7. 陈二春, 袁志明。文化移情能力与跨文化意识研究。四川外语学报。2008。24(3)第138-

140页。(Юань Чжимин.ЧэньЭрчунь. Культурная способность к эмпатии и кросс-культурная осведомленность [J]. Журнал образования иностранных языков провинции Сычуань, 2008,24 (3):.C138-140) 